Volume 8. No. 6, June 2020

International Journal of Emerging Trends in Engineering Research

Available Online at http://www.warse.org/IJETER/static/pdf/file/ijeter71862020.pdf

https://doi.org/10.30534/ijeter/2020/71862020

\title{
Studying Energy Efficiency of Thermal Management Systems Designed for Electric Vehicles with In-Wheel Motors
}

\author{
Ilya Kulikov, Kirill Karpukhin \\ Federal State Unitary Enterprise Central Scientific Research Automobile and Automotive Institute "NAMI"
}

(FSUE «NAMI»), Moscow, Russia

\begin{abstract}
The article describes a study aimed at evaluation of thermal management systems (TMS) intended for traction electric drives in respect of thermal performance and energy efficiency. Several options of TMS design have been devised for an all-wheel-drive vehicle equipped with in-wheel electric motors. The mathematical models of these systems have been elaborated in order to estimate their operating characteristics. The models include hydraulic and thermal behavior of powertrain components, as well as their energy performance in operating regimes corresponding to realworld vehicle driving. An additional purpose of the models is to be used in $\mathrm{X}$-in-the-loop environment, which merges physical tests and real-time software calculations in order to reproduce the operating behavior of complex powertrain systems. The simulations were conducted in two driving cycles intended for light-duty vehicles. The results allowed estimating both thermal and energy characteristics of the TMS and selecting the optimal topology for implementation within the $\mathrm{X}$-in-the-loop environment.
\end{abstract}

Key words: electric vehicle, powertrain, traction electric drive, in-wheel motor, thermal management system, mathematical modeling, energy efficiency, X-in-the-loop.

\section{INTRODUCTION}

The component-in-the-loop technology constitutes a synthesis of simulations and laboratory experiments implementing bilateral real-time interaction between virtual and physical parts of tested objects and systems. This interaction is implemented in two domains - information and physical. Parameters of the tested hardware components are measured and converted into signals fed into the model, which simulates behavior of virtual system's components and then transform this behavior into physical actuation by means of hardware simulators, which, in turn, apply this physical response to the tested components therefore closing the loop. Today's technologies allow to extend this approach beyond the limits of a single laboratory and connect several geographically scattered facilities into a network with the physical and virtual components distributed between these facilities with their operation synchronized in real-time. An example of such an environment is being currently developed in international collaboration between European and Russian research centers called the X-in-the-loop project (XiL project). It is aimed at research and development of powertrain systems for electric vehicles. Hardware components of developed systems are situated in laboratories of different institutions; mathematical models replicate those components, which are not yet implemented in hardware. For example, one of the project's laboratories houses a facility intended for tests of traction electric drives and regenerative braking systems [1]. Its counterpart is situated in another country and intended for testing of thermal management systems (TMS) for high voltage components of traction electric drives. The two laboratories interact via internet and share the information necessary for real-time synchronization of their test facilities in order to replicate operation of the entire powertrain.

The XiL project is aimed at elaboration of an advanced powertrain intended for passenger electric vehicles. Particularly, a production electric vehicle, which baseline version is equipped with two induction motors (one per axle), is being modified by replacing the induction motors with four permanent magnet in-wheel motors.

The TMS to be implemented within the XiL environment is a new system whose design is being elaborated especially for the said four-wheel-drive electric powertrain. A number of TMS layouts were devised based on the solutions developed in previous projects. The task of this study is to analyze these layouts and select one of them for implementation within the XiL environment. The analysis is to be conducted by means of a mathematical model, which simulates TMS operation within a vehicle driving in realworld conditions. The second purpose of this model (at least for one of its parts) is to be embedded within the XiL environment. Before interfacing with the hardware part of the XiL system, the model needs to be verified within a pure software environment (so-called software-in-the-loop technique).

The remainder of the article is organized as follows. The next section presents the TMS designs to be modeled and analyzed. It is followed by the sections describing the 
Ilya Kulikov et al., International Journal of Emerging Trends in Engineering Research, 8(6), June 2020, 2654 - 2662

elaborated mathematical models and the performed simulations, accompanied by the discussion of the simulation results and obtained characteristics of the thermal management systems. In the final section, conclusions are drawn about selection of the TMS to be implemented within the XiL system. The future work is also outlined.

\section{THERMAL MANAGEMENT SYSTEM DESIGN}

When elaborating the possible designs of the TMS, the following powertrain specifics were taken into consideration. The powertrain consists of four "invertermotor" pairs located near- or within (in the case of motors) the wheels. The powertrain control system is capable of individual regulation of each electric drive entailing individual thermal regimes thereof. The traction battery was not included in the scope of this study intended to become a topic of further work. Having analyzed the outcomes of the previous projects on TMS $[2,3]$ and the publications of other developers and researchers [4-9], a number of possible TMS layouts were devised shown in Figure 1. In this figure, "EM" stands for an electric machine (i.e. in-wheel motor), and "Inv" denotes an inverter. The expansion circuit is neglected in these drawings, as well as in the mathematical models described in the next section, due to its low relevancy to the operating regimes considered in the study.

The layouts presented in Figure 1 differ from each other in respect of the component arrangement. The designs can be divided into two main types based on the number of employed coolant pumps. The first type (Type A) uses two pumps while the second type (Type B) includes four pumps. Within a given layout type, there are the design variants differing in hydraulic connections between the electric drive components - either these connected in series or in parallel. Table 1 contains the key characteristics, including the hydraulic connection types, of all the devised layouts.
Type A, var. 1

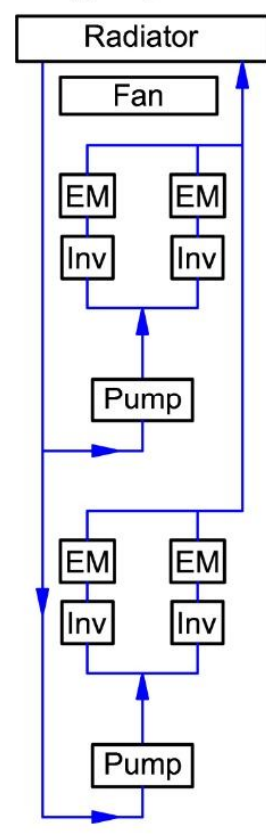

Type A, var. 2

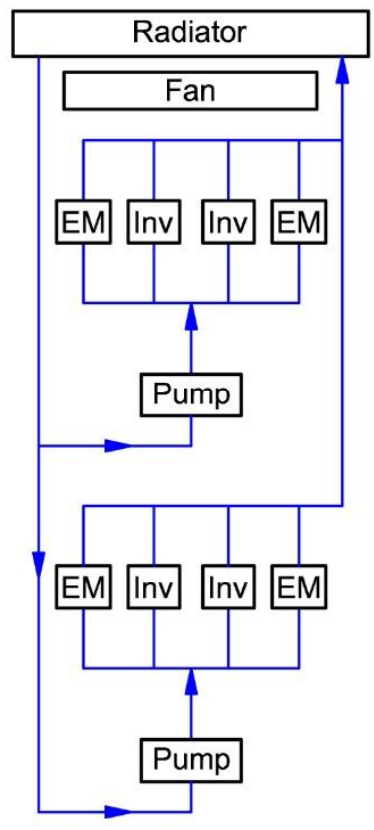

Type B, var. 1

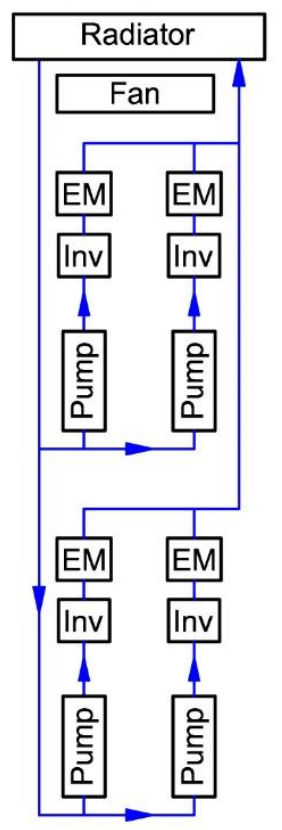

Type B, var. 2

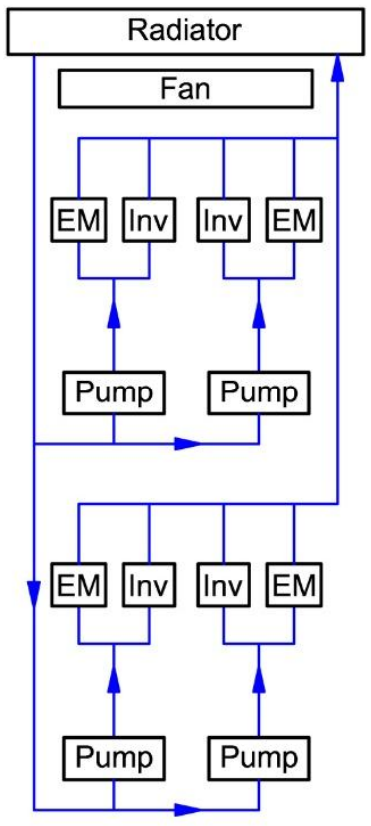

Type B, var. 3

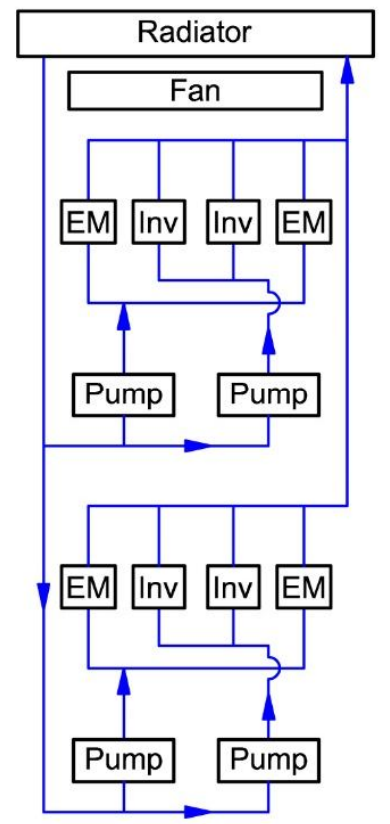

Figure 1: Possible layouts of the thermal management system

Table 1: Key design features of the thermal management system layouts

\begin{tabular}{|c|c|c|c|c|c|}
\hline \multirow{2}{*}{ TMS layout } & \multicolumn{2}{|l|}{ Type A } & \multicolumn{3}{|l|}{ Type B } \\
\hline & Variant 1 & Variant 2 & Variant 1 & Variant 2 & Variant 3 \\
\hline Number of pumps & 2 & 2 & 4 & 4 & 4 \\
\hline $\begin{array}{c}\text { Hydraulic } \\
\text { connection type }\end{array}$ & Series & Parallel & Series & Parallel & Parallel \\
\hline $\begin{array}{l}\text { Connected } \\
\text { components }\end{array}$ & Inverter-EM & Inverter-EM & Inverter-EM & Inverter-EM & $\begin{array}{l}\text { EM-EM, } \\
\text { inverter }\end{array}$ \\
\hline
\end{tabular}

The characteristic dimensions of the TMS are defined by the main vehicle geometric parameters, which are the wheelbase
(2900 $\mathrm{mm})$, the wheel track $(1650 \mathrm{~mm})$, and the front overhang (920 mm). 
Ilya Kulikov et al., International Journal of Emerging Trends in Engineering Research, 8(6), June 2020, 2654 - 2662

\section{MATHEMATICAL MODELS}

Since the part of the TMS model, which includes the components of the electric drive, is meant to be embedded into the XiL environment, it is advisable that at least this part complies with the requirements imposed by the XiL technology. The main of these is the capacity for real-time operation including calculations and interaction with external systems. This condition is usually met by lumped parameter models [8-11]. The structure and the "modus operandi" of the XiL system require simulating the thermal behavior of the traction electric drive components, which implies elaboration of corresponding models. When performing the software verification of these models, it is convenient if the models of other TMS components were also lumped mass systems. Therefore, this modeling approach was employed for both hydraulic and thermal parts of the TMS, as well as the traction electric drive and the vehicle itself. In order to implement the elaborated models within simulation software, a discretization (and formalization) method was employed called the bond graphs [12]. It allows the model to be implemented within a software as standardized sets of equations (and other mathematical entities) having unified input and output interfaces allowing to assemble systems of arbitrary complexity. In turn, this allows organizing the model in accordance with the actual structure of the modeled objects.

The structure of the TMS can be decomposed into discrete components whose hydraulic behavior is simulated by basic hydraulic elements of three types: inertial, elastic, and dissipative. The first of these constitutes a fluid's mass, which is transferred through a pipeline at a given flow rate resulting from applying of a given pressure. Assuming that any pipeline can be divided into $n$ components having constant cross-section areas, the flow rate $Q$ through a given pipeline is calculated from the following differential equation:

$$
\hat{Q}=\frac{p_{i m}+\sum_{i=1}^{n} \Delta p_{i}-p_{o w s}}{\sum_{i=1}^{n} k_{m a s s i}}
$$

where $p_{i n}$ and $p_{\text {out }}$ are the pressures at the pipeline's input and output respectively, $\Delta p_{i}$ is the differential pressure of the pipeline's $i$-th component, $k_{\text {massi }}$ is the hydraulic mass coefficient of the pipeline's $i$-th component. $k_{\text {mass } i}$ constitutes a quotient of the fluid's mass housed by the pipeline's component and the squared cross-section area of the component.

The elastic element is a hydraulic node, which connects at least two pipelines having known flow rates. A generic node aggregates $n$ pipelines and exerts pressure calculated with the following equation:

$$
\dot{p}-\gamma_{\text {noas }} \sum_{i=1}^{n} Q_{i}
$$

where $\gamma_{\text {naze }}$ is the hydraulic stiffness of the node, which constitutes a ratio of the lumped bulk modulus and the volume of the aggregated pipelines.

The dissipative hydraulic element is also known as the hydraulic resistance, which creates fluid pressure drop. While hydraulic resistances of ordinary pipes can be calculated with the formulae known from the literature [13], such units as radiator, electric motor, and inverter have complex hydraulic ducts whose resistances are usually obtained experimentally and approximated by polynomials. In practice, a second order function of the flow rate usually proves itself sufficient:

$$
\Delta p=k_{p 1} Q^{2}+k_{k 2} Q \text {. }
$$

The parameters $k_{p 1}$ and $k_{p 2}$ are identified from experimental data. Figure 2 shows the hydraulic resistance approximations for the components employed in this work.
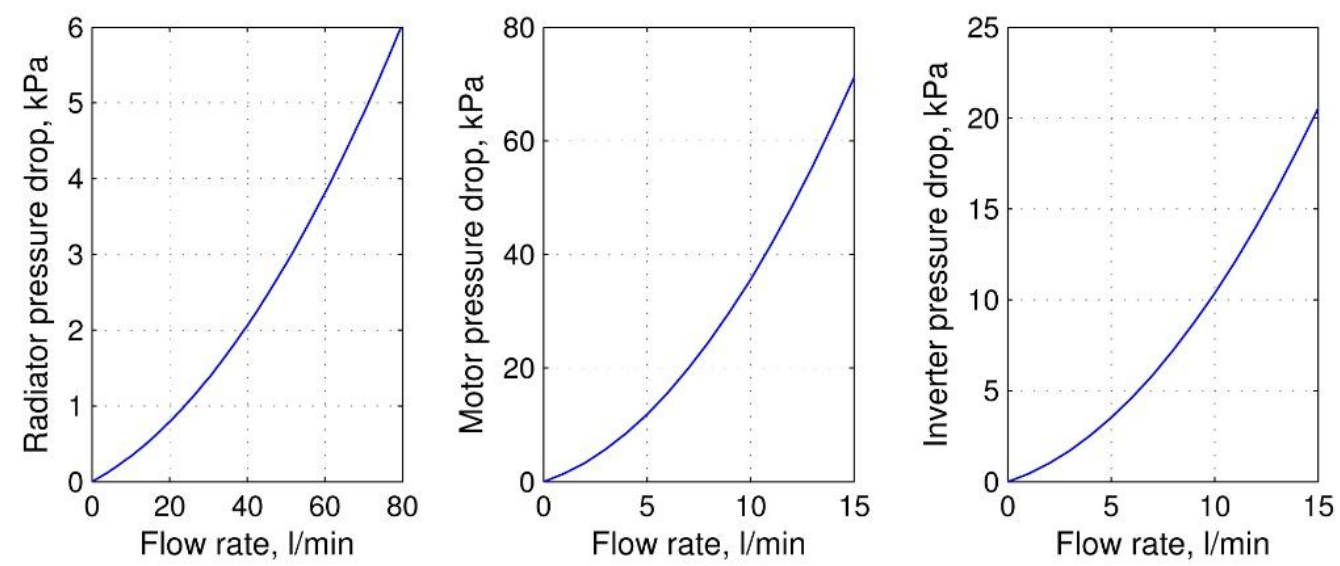

Figure 2: Approximated hydraulic resistances of the radiator, motor, and inverter

One can notice a significant difference in the hydraulic

resistances of the in-wheel motor and the inverter. It is of particular interest to compare the TMS layouts having series and parallel connections of these components taking into 
account this difference and its influence on the power needed to provide the required coolant flow rates.

Yet another hydraulic component to be modeled is the coolant pump. The pressure characteristics of mechanically driven pumps employed in conventional powertrains constitute functions of coolant flow rate and pump shaft rpm. The latter is proportional to the engine shaft speed [14]. When considering an electric powertrain, the pumps used in the TMS are powered from the traction battery through a voltage converter and driven by small electric motors. Therefore, the pressure control characteristics of such an electrohydraulic pump should include the control command of the electric motor rather than the shaft rpm. Given this modification, one can use the known approximating expression [14] for the pump characteristics:

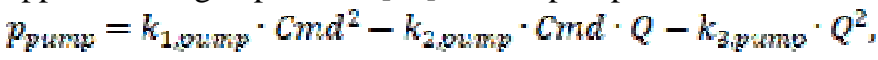

where $p_{\text {m:mm }}$ is the differential pressure exerted by the pump; Cmd is the command signal controlling the differential pressure; $k_{1, \text { wump }}, k_{2, \text { wump, }}$ and $k_{2, v u m p}$ are experimentally obtained parameters.

Since the study is aimed at assessment of the TMS system energy performance, besides the hydraulic characteristics of the pump its efficiency map is also to be taken into account. Figure 3 shows both these characteristics. In the left graph, "Exp. data" denotes pressure data obtained in laboratory experiments; "Approx." denotes the approximating lines obtained with the above formula after identification of its parameters. The values of the command signal define the duty cycle ratio of pulse width modulation. The efficiency map was built from the experimental data, which included both the hydraulic operating parameters of the pump (i.e. coolant flow rate and differential pressure) and parameters of the electric power source (current and voltage).
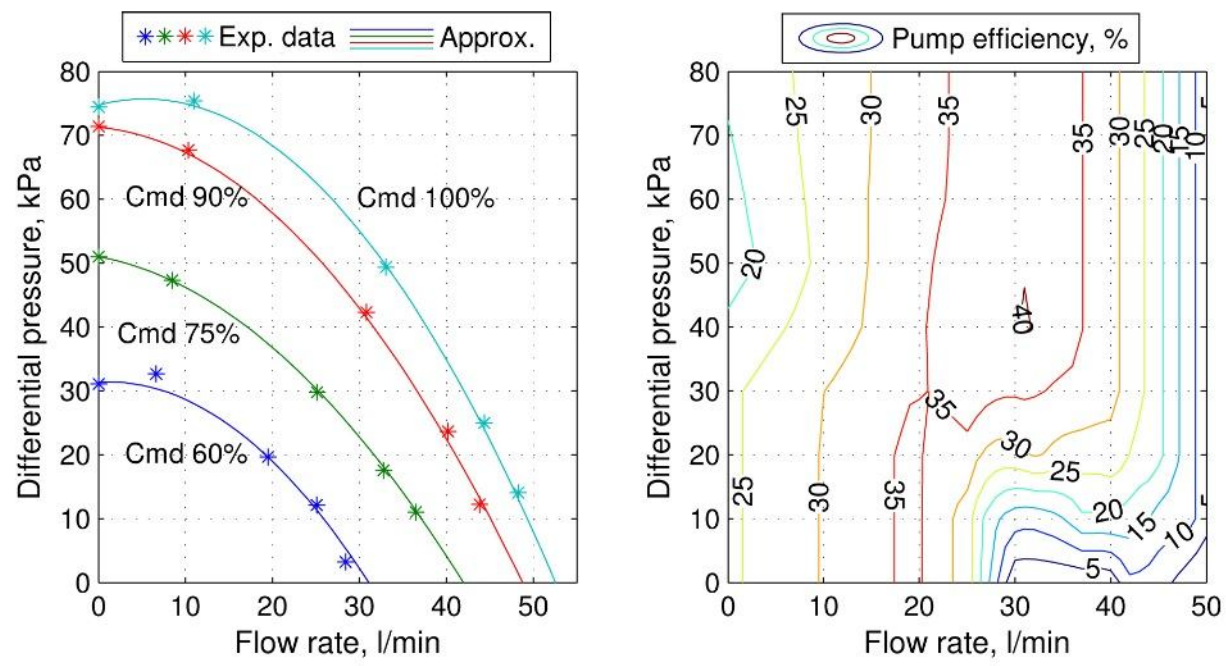

Figure 3: Characteristics of the electrohydraulic pump. Left - pressure control, right - efficiency map

Given the flow rate and the pressure created by the pump and its efficiency $\eta_{\text {mismm, }}$ one can obtain the electric power consumed by the pump using the equation of power equilibrium:

$$
P_{\text {wamplel }} \cdot \eta_{\text {puraw }}-p_{\text {wump }}-Q \text {. }
$$

In order to simulate thermal behavior of the TMS components, a generic thermal model has been elaborated, which includes three lumped masses: the coolant flowing through the component's ducts, the component's body, and the ambient medium (i.e. air). Convective heat transfer takes place between the surfaces associated with the said masses. Heat is transferred from the component's body to the fluid mass (or vice versa) through the surface of the hydraulic ducts (i.e. cooling circuit or radiator tubes). Convective heat transfer from the body to the ambient is enforced by the air flowing through the outside ducts or along the component's surface. The actual heat flow is generated within a volume located in certain place, which is separated from the coolant by a wall. The thicker the wall, the slower the heat transfer into the coolant. However, this cannot be implemented in the case of lumped masses. The heat source affects the entire lumped mass. In order to simulate how remote the heat source from the coolant is, the heat power is divided between the lumped masses of the component's body and the fluid in a certain proportion defined by weighting factors. The closer the heat source to the fluid, the higher the corresponding weighting factor and vice versa. These assumptions yield the following system of equations describing the three-mass thermal component: 
Ilya Kulikov et al., International Journal of Emerging Trends in Engineering Research, 8(6), June 2020, 2654 - 2662

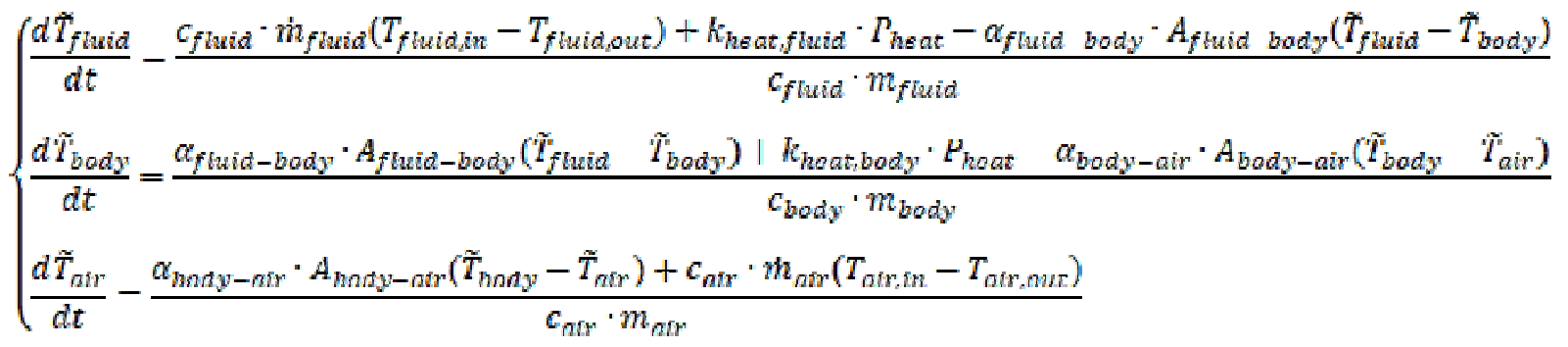

where $\tilde{T}$ is the average temperature; $T_{\text {m.m }}$ and $T_{\text {nurout }}$ are the temperatures at the fluid (or air) inlet and outlet respectively, $\boldsymbol{m}_{w}$ and $\boldsymbol{c}_{\text {.. }}$ are the mass and the specific thermal capacity of a given lumped object; $\alpha_{\ldots-1} \ldots$ is the coefficient of convective heat transfer along the surface of two adjacent lumped masses; $A_{\ldots . . . . . .}$ is the surface conducting the convective heat transfer; $P_{\text {hear }}$ is the heat power dissipated within the component; $k_{\text {hat, fiuid }}$ and $k_{\text {Reatbody }}$ are the heat power weight factors of the fluid and body respectively. The weight factors should satisfy the following condition: $k_{\text {heat, fuid }}+k_{\text {heat body }}=1$.

The heat transfer coefficients were calculated using known formulas $[7,15,16]$ based on geometry and material properties of the components and their fluid and air ducts. The in-wheel motor has a coil-type cooling jacket having the active diameter of $450 \mathrm{~mm}$. The inverter has a heat sink with the following dimensions: $190 \mathrm{~mm}$ x $55 \mathrm{~mm}$ x $8 \mathrm{~mm}$. The employed radiator is of the tube-fin cross-flow type having the following dimensions: $720 \mathrm{~mm} \times 590 \mathrm{~mm} \times 45$ $\mathrm{mm}$.

The thermal model of the radiator was validated using experimental data obtained at a test bench in steady-state operating regimes. The average errors of temperature

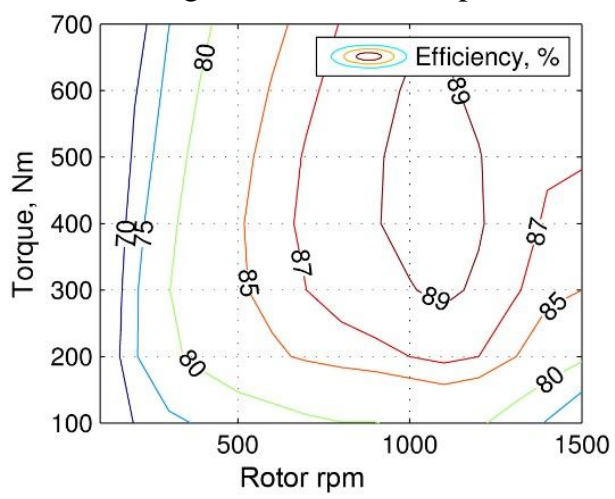

calculation amounted $2.6 \%$ for the air and $5.5 \%$ for the coolant. The absolute error values did not exceed $3{ }^{\circ} \mathrm{C}$. These results allowed considering the radiator model sufficiently accurate.

The heat power dissipated by the motors and inverters is calculated using the operating parameters and efficiency characteristics of these components:

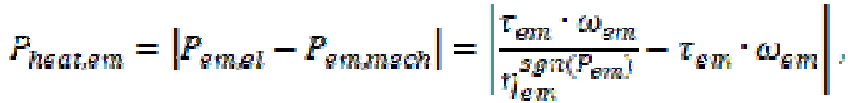

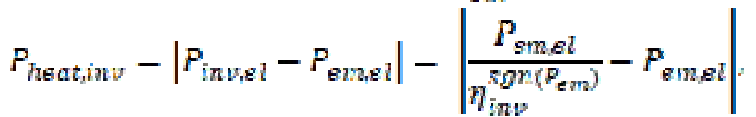

where $P_{\text {emmech and }} P_{\text {emsl }}$ are the mechanical and electric power of the electric machine (in-wheel motor), $F_{\text {inusi }}$ is the electric power at the inverter's input (i.e. battery power), $\eta_{A m}^{\operatorname{sgn}\left(P_{e m}\right)}$ and $\eta_{i n n}^{\operatorname{sgn}\left(\mathcal{P}_{\mathrm{Rm}}\right)}$ are the efficiencies of the electric machine and inverter, $\tau_{e m i}$ and $\omega_{e m}$ are the torque and angular speed of the $i$-th electric machine.

Figure 4 shows the electric drive (inverter + in-wheel motor) characteristics of efficiency and heat power dissipation in the continuous operating mode. In the model, these characteristics are separated into the motor part and the inverter part.

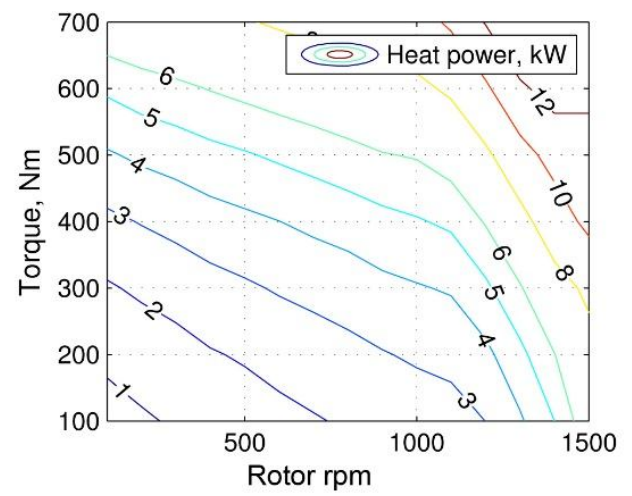

Figure 4: Characteristics of the traction electric drive. Left - efficiency, right - heat power

The parameters of the traction electric drive components were calculated in operating conditions simulated by driving cycles. In order to do this, a simple model of vehicle dynamics was elaborated. The following assumptions were made while deriving this model. The vehicle motion was considered linear neglecting tire slip, dynamics of vertical forces, and variation of wheel radii. The assumptions allowed to present vehicle motion as dynamics of a single lumped mass:

$$
v-\frac{2_{i=1}^{i} \tau_{e m i} / r_{w}-F_{w}-F_{f}}{m_{p}+n\left(g_{e m}+g_{w}\right) / r_{w}^{2}}
$$

where $\boldsymbol{m}_{w}$ is the vehicle mass; $T_{w}$ is the wheel radius; $\boldsymbol{2}_{\boldsymbol{m}}$ and $\mathcal{X}_{w}$ are the electric machine and wheel rotational 
Ilya Kulikov et al., International Journal of Emerging Trends in Engineering Research, 8(6), June 2020, 2654 - 2662

inertias; $n$ is the number of vehicle's wheels; $F_{\mathrm{w}}, F_{f}$ are the air drag and rolling resistance forces. The grade resistance was neglected, since the employed driving cycles simulate level roads. The vehicle velocity relates to the motor angular speed as follows: $\omega_{e m}{ }^{*}=v$.

The air drag force is calculated by means of the empirical formula:

$$
F_{v t}=0.5 \cdot C_{x} \cdot A_{v} \cdot P_{c a r} \cdot v^{2},
$$

where $C_{x}$ is the vehicle air drag coefficient; $A_{v}$ is the frontal area of the vehicle, $\rho_{\text {air }}$ is the air density.

The rolling resistance force is calculated with the following expression: $F_{f}=m_{v} \cdot g \cdot f$, where $g$ is the gravity constant, and $f$ is the tire rolling resistance coefficient. The latter is approximated by the known empirical formula [17]: $f^{\prime}=f_{0}+k_{v} \cdot v_{v e h}^{2}$, where $f_{0}^{f}$ characterizes the rolling resistance at near zero velocity, and $k_{v}$ is the factor of velocity-dependent growth of the rolling resistance.

The numerical values of the parameters used in the vehicle dynamics model are listed in Table 2.

Table 2: Parameters for the model of vehicle dynamics

\begin{tabular}{|l|l|l|l|l|l|l|}
\hline $\begin{array}{l}m_{v}, \\
\mathrm{~kg}\end{array}$ & $\tau_{\mathrm{w}}^{*}, \mathrm{~m}$ & $\begin{array}{l}\mathcal{I}_{g m}+\mathscr{I}_{w}, \\
\mathrm{~kg} \cdot \mathrm{m}^{2}\end{array}$ & $\boldsymbol{C}_{x}$ & $\boldsymbol{A}, \mathrm{m}^{2}$ & $f_{0}$ & $\boldsymbol{K}_{v}$ \\
\hline 3130 & 0.365 & 2 & 0.3 & 2.65 & 0.008 & $4 \cdot 10^{-6}$ \\
\hline
\end{tabular}
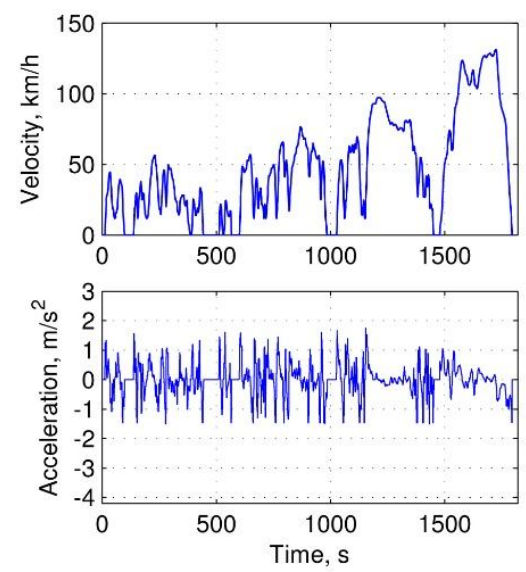

\section{RESULTS AND DISCUSSION}

The simulations performed by means of the elaborated model reproduced the following operating conditions of the vehicle and the TMS. The ambient temperature was set to its maximum $\left(45{ }^{\circ} \mathrm{C}\right)$ permitted by the operating conditions specified for the vehicle. On the contrary, the coolant flow rates through the electric drive components were set to the admissible minima ( $8 \mathrm{l} / \mathrm{min}$ - motor, $5 \mathrm{l} / \mathrm{min}$ - inverter) specified by the manufacturers thereof. Note that the latter condition is only met if the TMS design allows so (i.e. provides independent regulation of the coolant flow rates through components with significantly differing hydraulic resistances). Additionally, the radiator's fan was inactive. In this way, severe and unregulated operating conditions were simulated in order to estimate the performance provided by the design solutions rather than control algorithms.

Two light-duty driving cycles shown in Figure 5 were employed, namely, the Worldwide Harmonized Light Vehicle Test Cycle (WLTC) and ARTEMIS [18] (city + suburban parts). The latter is more intensive, containing accelerations up to $2.9 \mathrm{~m} / \mathrm{s}^{2}$ and decelerations up to $4 \mathrm{~m} / \mathrm{s}^{2}$ (see the bottom graphs in Figure 5). Therefore, it entails increased thermal loading of the powertrain components.
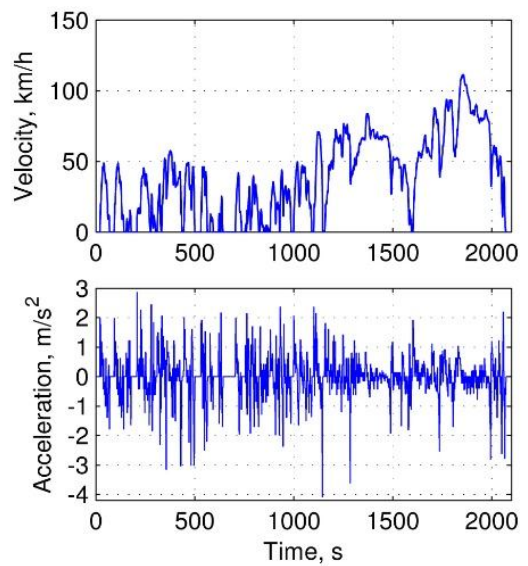

Figure 5: Employed driving cycles. Left - WLTC, right - ARTEMIS (city + suburban)

The heat transfer coefficients were being calculated dynamically during the simulations. From the simulation results, maximum values of these coefficients were calculated amounting $2700 \ldots 3200 \mathrm{~W} /{ }^{\circ} \mathrm{C}$ and up to 3500 $\mathrm{W} /{ }^{\circ} \mathrm{C}$ for the radiator water-body and body-air heat transfer respectively, $700 \ldots 800 \mathrm{~W} /{ }^{\circ} \mathrm{C}$ for the motor body-fluid heat transfer, and $17 \ldots 21 \mathrm{~W} /{ }^{\circ} \mathrm{C}$ for the inverter body-fluid heat transfer.

Figure 6 presents a fragment of simulation results in the ARTEMIS driving cycle where the highest temperatures of the powertrain components were reached. The "Wheel power" plot shows the total mechanical power of four inwheel motors. In the "Heat power" graph, there are two lines, one of which corresponds to the total heat power emitted by the electric drive components (motors and inverters) and the second shows the heat power dissipated by the radiator into ambient. In two bottom graphs, one can see the temperatures of the "warmest" in-wheel motor (denoted as "EM") and inverter for all the considered TMS layouts (excluding the Type A, variant 2 due to the causes explained below). From these plots, it is clear that the layouts containing series connections of the components are least efficient in the sense of thermal performance, because the motors are supplied with the coolant, which is already heated by the preceding inverters. Both the "warmest" motor and the inverter approached their maximum input coolant 
temperatures, above which their power would be derated. Of course, these temperatures were obtained with the minimal coolant flow rates. On the other hand, in more severe operating conditions (for example, intensive mountain driving), one cannot exclude the possibility of reaching the derating threshold even with increased flow rate. These considerations suggest investigation of wider operating conditions, including highly intensive driving, in the further work.

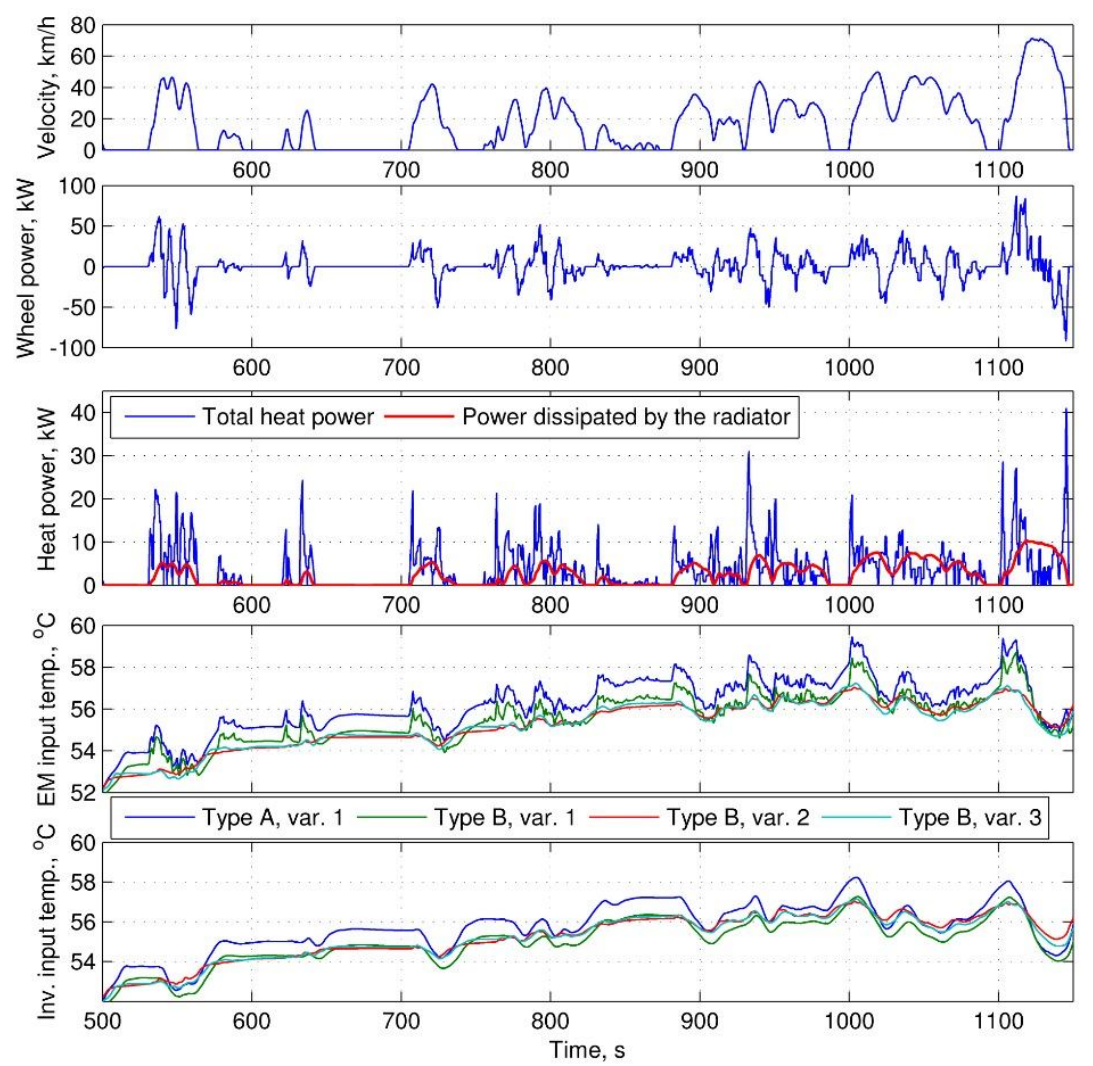

Figure 6: Example of simulation results in the ARTEMIS driving cycle (fragment)

The simulations showed that the layout Type A, variant 2 is hardly affordable for systems with different hydraulic resistances of the components. When trying to supply the minimum required coolant flow rate through the motors, the inverters, arranged in parallel, are fed with the flow rate exceeding the sufficient one by a factor of 3 , which entails the proportional increase of the pump's power. As a result, the pumps reach their maximum power, but even then they are not able to deliver the required minimum coolant flow rate through the motors. Therefore, for this layout, one should either use larger pumps or increase the number thereof. The first option was ruled out due to the necessity of having unified components for different TMS applications. The second option can be implemented by pairs of the pumps connected either in series or in parallel. The series connection, although increases the system's maximum differential pressure, does not extend its operating range in respect of the flow rate whose shortage does not allow fulfilling even minimum operating requirements of the motors. Using the parallel connection transforms the system into the Type B, variant 2 . Thus, the layout of the Type A, variant 2 was excluded from consideration. It should be noted that this shortcoming also takes place, although to a lesser extent, in the layout Type B, variant 2 due to the parallel connections of the components with significantly differing hydraulic resistances.

The power consumption and efficiency data of the electrohydraulic pumps obtained in the simulations are summarized in Table 3.

Table 3: Power consumption and efficiency data resulted from the simulations

\begin{tabular}{|c|c|c|c|c|c|}
\hline \multirow{2}{*}{ TMS layout } & \multicolumn{2}{|l|}{ Type A } & \multicolumn{3}{|l|}{ Type B } \\
\hline & Variant 1 & Variant 2 & Variant 1 & Variant 2 & Variant 3 \\
\hline Power consumption of the pumps, $\mathrm{W}$ & 54.4 & $130^{*}$ & 62 & 144 & 50.1 \\
\hline Operating efficiency of the pumps, $\%$ & $32 \ldots 32.5$ & $26 \ldots 29$ & $28 \ldots 28.5$ & 38 & $30 \ldots 33$ \\
\hline
\end{tabular}


Ilya Kulikov et al., International Journal of Emerging Trends in Engineering Research, 8(6), June 2020, 2654 - 2662

* The maximum power of two pumps.

\section{CONCLUSIONS AND FUTURE WORK}

Among the analyzed TMS layouts, the one containing four pumps and parallel hydraulic connections between the pairs "inverter-inverter" and "motor-motor" can be considered as the optimal. It has the lowest electric power consumption, the highest flexibility of controlling thermal states of the powertrain components, and finally yet importantly provides the highest overheat proof. Its shortcomings relate to the system structure and cost, namely, the use of two extra pumps and the need for more complex pipelines in order to connect hydraulically the components situated on opposite sides of the vehicle's chassis.

The conducted simulations have also shown that the layouts containing series hydraulic connections of the powertrain components, although efficient in respect of power consumption, have lower thermal performance than their parallel counterparts do. This, in turn, increases the risk of reaching the derating temperatures during intensive driving in high ambient temperatures.

The layouts containing parallel connections of components with significantly different hydraulic resistances have high power consumption due to excessive coolant flow rate. The latter is inevitably created through the components with lower resistances. Therefore, this layout type can only be worthwhile in cases when the hydraulic resistances of the powertrain components are approximately equal.

There are a number of tasks to be solved in the sequel of the present study:

- Investigate thermal and energy characteristics of the devised TMS in wider operating conditions including highly intensive driving.

- Implement the optimum TMS layout and its control system within the XiL environment.

- Perform tests of the developed electric powertrain and its thermal management system in cooperation with other laboratories involved in the XiL system.

\section{ACKNOWLEDGEMENT}

The article was prepared under the agreement \# № 075-112019-080 (05.628.21.0015) with the Ministry of science and higher education Russian Federation (unique project identifier RFMEFI62819X0015).

\section{REFERENCES}

1. V. Ivanov, K. Augsburg, C. Bernad, M. Dhaens, M. Dutré, S. Gramstat, P. Magnin, V. Schreiber, U. Skrt, N. Van Kelecom. Connected and Shared X-in-the-Loop
Technologies for Electric Vehicle Design. World Electr. Veh. J. no. 10, p. 83, 2019. https://doi.org/10.3390/wevj10040083

2. K.E. Karpukhin, A.A. Shorin, A.S. Terenchenko, V.N. Kondrashov. The steps of creating an experimental system for accumulation and storage of electrical energy. ARPN journal of engineering and applied sciences vol. 12 no. 13, pp. 4189 - 4195, 2017.

3. R.Kh. Kurmaev, A.A. Umnitsyn, A.S. Terenchenko, K.E. Karpukhin. Develompent of high voltage battery with thermostatic system for electric vehicles. International journal of mechanical engineering and technology vol. 9 no. 7, pp. 1340-1346, 2018.

4. Y. Wang, Q. Gao, T. Zhang, G. Wang, Z. Jiang, Y. Li. Advances in Integrated Vehicle Thermal Management and Numerical Simulation. Energies no. 10, p. 1636, 2017.

5. T.A. Weustenfeld, W. Bauer-Kugelmann, J.C. Menken, K. Strasser, J. Köhler. Heat Flow Rate Based Thermal Management for Electric Vehicles using a Secondary Loop Heating and Cooling System. Proc. of the Vehicle Thermal Management Systems Symposium and Exhibition (VTMS). Nottingham, UK, 10-13 May 2015.

6. J. Huang, S.S. Naini, R. Miller, D. Rizzo, K. Sebeck, S. Shurin, J. Wagner. A Hybrid Electric Vehicle Motor Cooling System-Design, Model, and Control. IEEE Transactions on Vehicular Technology, vol. 68, no. 5, pp. 4467-4478, 2019.

https://doi.org/10.1109/TVT.2019.2902135

7. M. Cao. Thermal and Cooling Systems Modeling of Powertrain for a Plug-in Parallel-Through-the-Road Hybrid Electric Vehicle. MSc Thesis. Wayne State University, pp. 29-68, 2014.

8. D. Leighton. Combined Fluid Loop Thermal Management for Electric Drive Vehicle Range Improvement, SAE Int. J. Passeng. Cars - Mech. Syst vol. 8 no. 2, pp. 711-720, 2015.

9. J.P. Rugh. Integrated Vehicle Thermal Management Combining Fluid Loops in Electric Drive Vehicles. Technical presentation NREL/PR-5400-58161. Vehicle Technologies Program Annual Merit Review, 2013.

10. C. Gross-Weege, T. Lichius, S. Baltzer, D. Abel. Control Design for a Thermal Hardware-in-the-Loop Test Bench for Automobile Thermal Management Systems. IFAC-PapersOnLine vol. 48 no. 15, pp. 441447, 2015. https://doi.org/10.1016/j.ifacol.2015.10.063

11. S. Baltzer, T. Lichius, J. Gissing, P. Jeck, L. Eckstein, J. Küfen. Hardware-in-the-Loop (HIL) Simulation with Modelica - A Design Tool for Thermal Management Systems. Proceedings of the 10th International Modelica Conference, 2014.

12. D.C. Karnopp, D.L. Margolis, R.C. Rosenberg. System Dynamics: Modeling, Simulation, and Control of 
Ilya Kulikov et al., International Journal of Emerging Trends in Engineering Research, 8(6), June 2020, 2654 - 2662

Mechatronic Systems. John Wiley \& Sons, Inc, pp. 1777, 2012.

13. V.P. Tarasik. Mathematical Modeling of Technical Systems. New Knowledge, Minsk, pp. 75-91, 2013.

14. R. Isermann. Engine Modeling and Control. Modeling and Electronic Management of Internal Combustion Engines. Springer-Verlag Berlin Heidelberg, pp. 238250, 2014.

15. J. LaMarre. FSAE Electric Vehicle Cooling System Design. Technical report, University of Akron, p. 46, 2015.

16. C. Oliet, A. Oliva, J. Castro, C.D. Perrez-Segarra. Parametric studies on automotive radiators. Applied Thermal Engineering vol. 27 no. 11-12, pp. 2033-2043, 2007.

https://doi.org/10.1016/j.applthermaleng.2006.12.006

17. G. Genta. Motor vehicle dynamics. Modeling and simulation. World Scientific Publishing Co. Pte. Ltd., pp. 43-44, 2006.

18. M. André, M. Keller, Å. Sjödin, M. Gadrat, I. McCrae, P. Dilara. The Artemis European Tools for Estimating the Transport Pollutant Emissions. Proc. of 16th International Transport and Air Pollution Congress, 2008. 